\title{
Feline Histoplasmosis in Brazil: Clinical and Laboratory Aspects and a Comparative Approach of Published Reports
}

\author{
Raimunda Sâmia Nogueira Brilhante • Camila Gomes Virginio Coelho • \\ José Júlio Costa Sidrim • Rita Amanda Chaves de Lima • Joyce Fonteles Ribeiro • \\ Rossana Aguiar de Cordeiro • Débora de Souza Collares Maia Castelo-Branco • \\ José Maurício Fonteles Gomes - Lucilene Simões-Mattos • Marcos Renato Franzosi Mattos • \\ Hugo Enrique Orsini Beserra • George Cândido Nogueira • Adriana de Queiroz Pinheiro • \\ Marcos Fábio Gadelha Rocha
}

Received: 18 May 2011/Accepted: 2 September 2011/Published online: 18 October 2011

(C) Springer Science+Business Media B.V. 2011

\begin{abstract}
The present study described clinical and epidemiological aspects of three cases of feline histoplasmosis and compared them to previously described cases. A detailed mycological identification and antifungal susceptibility profile of each isolate are presented. Secondarily, a serological survey for antiHistoplasma antibodies was performed with domestic and wild cats. Diseased animals presented nodular to ulcerated skin lesions and respiratory disorders as main clinical signs. $H$. capsulatum var. capsulatum was isolated and the strains showed to be susceptible to antifungal drugs. Considering that feline histoplasmosis is uncommonly observed in veterinary clinics, diagnosis, and clinical management in endemic areas should be improved.
\end{abstract}

\footnotetext{
R. S. N. Brilhante · J. J. C. Sidrim .

R. A. C. de Lima - J. F. Ribeiro - R. A. Cordeiro •

D. S. C. M. Castelo-Branco - M. F. G. Rocha

Department of Pathology and Legal Medicine,

College of Medicine, Specialized Medical Mycology

Center, Post-Graduation Program in Medical

Microbiology, Federal University of Ceará, Fortaleza,

Ceará, Brazil
}

\section{R. S. N. Brilhante - J. J. C. Sidrim - R. A. Cordeiro}

Post-Graduation Program in Medical Sciences,

Federal University of Ceará, Fortaleza, Ceará, Brazil

\section{R. S. N. Brilhante $(\bowtie)$}

Rua Barão de Canindé, 210, Montese, CEP: 60.425-540

Fortaleza, Ceará, Brazil

e-mail: brilhante@ufc.br
Keywords Cats $\cdot$ Felids $\cdot$ Histoplasma capsulatum . Antifungal susceptibility profile $\cdot$ Serologic survey

\section{Introduction}

The causative agent of histoplasmosis, the dimorphic fungus Histoplasma capsulatum var. capsulatum, exists in the environment as a mycelium-producing saprophytic species in the soil and is widely distributed throughout the world. It infects many mammals, including dogs, cats, and humans, [1, 2] and the resulting disease is considered the second most common systemic mycosis in cats [1]. Although it has been reported that feline histoplasmosis in

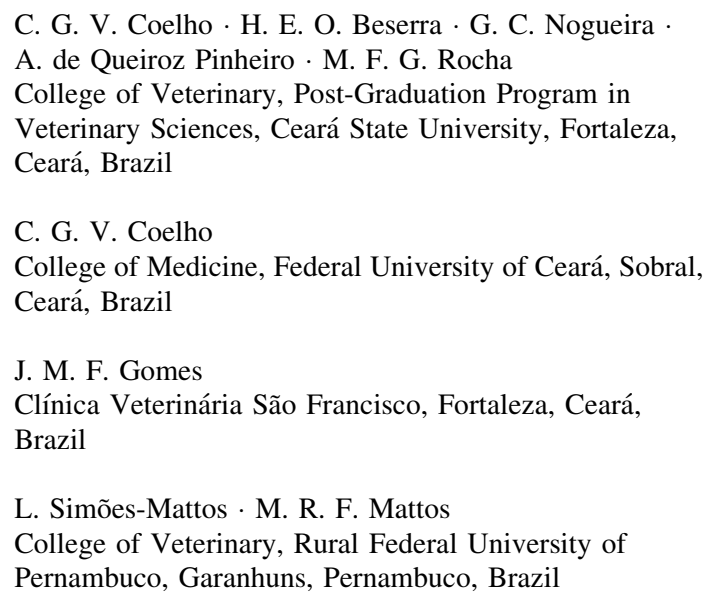


tropical, subtropical, and temperate areas is frequent $[3,4]$, little information is available on feline histoplasmosis in Brazil, where only one case of the disease was reported in a domestic cat [5]. Considering the importance of histoplasmosis for Veterinary Mycology, as well as the scarcity of case reports in small animals, three cases of feline histoplasmosis in Brazil are presented in this study, with emphasis on clinical and phenotypical findings. In addition, data of a serological survey conducted with domestic and wild felids from the region are presented.

\section{Methods}

\section{Case 1}

A 6-year-old Siamese castrated male cat, from the city of Sobral $\left(3^{\circ} 41^{\prime} \mathrm{S}-40^{\circ} 20^{\prime} \mathrm{W}\right)$, Ceará State, Northeastern Brazil. The animal lived in house and was allowed free outdoor access; initially, the cat presented good general conditions, with normal body temperature and hydration status, but discrete lymphadenomegaly and a non-ulcerated nasal mass, with approximately 2 months of evolution. Complete blood count and serum chemical profiles were within normal ranges and no clinical or serological evidences for other diseases, such as FeLv (feline leukemia virus) or FIV (feline immunodeficiency virus) were observed. Biopsy fragments were obtained from the borders of the nasal mass, for microbiological and histopathological analyses, through a surgical procedure, under anesthesia with association of xylazine $(1 \mathrm{mg} / \mathrm{Kg})$ and ketamine $(10 \mathrm{mg} / \mathrm{Kg})$. Based on microbiological results, the cat was initially treated with itraconazole $(10 \mathrm{mg} / \mathrm{Kg})$, orally, every $24 \mathrm{~h}$, for 21 days. Treatment was suspended because the animal started to vomit, leading to clinical and prognostic worsening. Finally, the owner chose to euthanize the animal.

\section{Case 2}

A 3-year-old mixed-breed male cat, native to the city of Baturité $\left(4^{\circ} 19^{\prime} \mathrm{S}-38^{\circ} 53^{\prime} \mathrm{W}\right)$, Ceará State, was investigated. The animal lived in a house surrounded by fruit trees and native vegetation, where other animals were also raised, such as chickens, pigeons, goats, dogs, and other cats were also seen. The cat presented two ulcers of approximately $1.5 \times 2.0 \mathrm{~cm}$ on the tail, near the anus, with 4 months of evolution. The ulcers presented elevated borders separated by a fine skin tissue and erythematous granulation tissue in the bed. Complete blood count, serum biochemical analyses, and serological tests for FeLv and FIV were not performed. An excisional biopsy of the lesion was performed, for microbiological and histopathological analyses, while the animal was under anesthesia with the association of xylazine $(1 \mathrm{mg} / \mathrm{Kg})$ and ketamine $(10 \mathrm{mg} / \mathrm{Kg}$ ). To evaluate the occurrence of primary lung infection, a thoracic X-ray was taken, but no alterations were observed. Therapy with itraconazole $(5 \mathrm{mg} / \mathrm{Kg}$ ), orally, every $24 \mathrm{~h}$, for 60 days, was attempted after mycological diagnosis, but the lesion did not regress. Twenty days after the end of the antifungal therapy, the cat suddenly became lethargic, apathetic, and unconscious and died. A necropsy was performed and the main findings were suggestive of feline urological syndrome (FUS).

Case 3

A 3-year-old mixed-breed female cat from Fortaleza $\left(03^{\circ} 41^{\prime} 15^{\prime} \mathrm{S}-38^{\circ} 29^{\prime} \mathrm{W}\right)$, Ceará State, was examined for presenting an enlargement of the nasal region, with nodules and purulent secretion, which obstructed the upper airway, causing respiratory distress. Through palpation, a fluctuating cervical nodule was detected. Pulmonary auscultation revealed the presence of secretion and thoracic radiographs evidenced the occurrence of pneumonia. In addition, complete blood count was within normal range, but biochemical analyses and serological tests for FeLv and FIV were not performed. Fine-needle aspiration biopsy (FNAB) of the nasal lesion was performed for cytological examination, which resulted in unspecific findings. Excisional biopsy was not performed. Besides FNAB, purulent exsudate from the nasal cavity was collected with a swab for bacteriological and mycological processing. The animal was treated with itraconazole (20 mg/Kg) orally, every $24 \mathrm{~h}$, for 3 months, which was efficient and caused remission of clinical signs.

\section{Classical Mycological Examination}

Mycological examination was performed at the Specialized Medical Mycology Center (CEMM) of Federal University of Ceará, Brazil. Clinical specimens 
obtained from the skin lesion of the three analyzed cats were inoculated in tubes containing agar Sabouraud, agar Sabouraud supplemented with chloramphenicol, and agar Sabouraud supplemented with chloramphenicol and cycloheximide. Macro and micromorphological characteristics were analyzed after 15-30 days of incubation at $28^{\circ} \mathrm{C}$, as previously described [6]. The strains were also grown on $10 \%$ Sabouraud blood agar and incubated at $35^{\circ} \mathrm{C}$ for reversion to yeast-like phase [7]. All procedures were performed within a class II biological safety cabinet in a biosafety level 3 laboratory.

\section{Antifungal Susceptibility Test}

Microdilution testing was performed in accordance with the guidelines of the document M38-A and M27A2 [8, 9] for mycelial and yeast-like phases, respectively, following the adaptations proposed by Brilhante et al. [7]. The three H. capsulatum isolates were tested against amphotericin B, itraconazole, voriconazole, caspofungin, and sulfamethoxazole-trimethoprim, since the latter has been successfully used for treating African histoplasmosis [10]. The results were visually read and interpreted according to previously described methodologies [7, 11]. Control strains (H. capsulatum var. capsulatum CEMM 03-4-036, Candida parapsilosis ATCC 22019, and C. krusei ATCC 6258) were used in order to assure the quality of the assays.

\section{Serological Survey}

The pursuit for the serum detection of anti-Histoplasma antibodies in cats was approved by the ethics committee of Ceará State University (Process 07381395-8). From January 2009 to June 2010, 131 serum samples from domestic cats were investigated, out of which 17 were from Sobral Zoonosis Control Center and 114 from Fortaleza (34 cats from veterinary clinics and 80 captured stray cats kept at Fortaleza Zoonosis Control Center or private shelters). In addition, six serum samples from wild felids were also collected, from four oncillas (Leopardus tigrinus) and two jaguarundis (Puma yagouaroundi) that were captured in the State of Ceará. The obtained serum samples were tested for the presence of anti-
Histoplasma antibodies by immunodiffusion (ID), using the Histoplasma ID Antigen (H \& M), according to the supplier's instructions (Immy Immunodiagnostics, Inc., USA). Positive serum samples were tested for cross-reactions with coccidioidal antibodies using C. immitis IDCF antigen, following supplier's instructions (Immy Immunodiagnostics, Inc., USA).

\section{Results and Discussion}

The mycological analyses confirmed the identification of $H$. capsulatum in the three analyzed cases, as demonstrated by the growth of filamentous colonies that were initially smooth and white, but became cottony and brownish as they grew older. Microscopically, they were composed of hyaline septate hyphae with micro and macroconidia, including tuberculate macroconidia. Additionally, reversion to yeast-like phase was achieved.

The present study reports the first cases of animal histoplasmosis in the state of Ceará, Northeastern Brazil. It is noteworthy that despite the scarcity of animal histoplasmosis in Ceará, this state has a high incidence of human disease, particularly among HIVpositive patients [2]. Thus, considering the endemicity of human histoplasmosis in Brazil [2], it is believed that this disease is also common among animals. However, few reports corroborate this belief, since, in Brazil, H. capsulatum has only been isolated from soil containing bird or bat excrement $[12,13]$ and from some animal species, such as dogs [14, 15], opossums (Didelphis albiventris) [16] and from one cat [5].

In cats, $H$. capsulatum infection is mostly inapparent or it may cause clinical pulmonary granulomatous or disseminated disease, involving many organic sites, including lymphnodes and integument [1]. Respiratory compromise was observed in cases 1 and 3, corroborating previously described data concerning the occurrence of respiratory alterations [17, 18], but only case 3 presented signs of pneumonia, associated with skin lesions, suggesting the occurrence of disseminated histoplasmosis. Curiously, the only case of feline histoplasmosis reported in Brazil, also described the occurrence of a nasal cutaneous mass associated with respiratory distress, but with no signs of pulmonary compromise [5]. In case 2, only skin lesions were observed, raising the possibility of the occurrence of primary cutaneous histoplasmosis. In 
Table 1 Main clinical findings of feline histoplasmosis from Ceará State, Brazil, compared with cases worldwide

\begin{tabular}{llll}
\hline Main clinical findings & $\begin{array}{c}\text { Cases from } \\
\text { Ceará state }\end{array}$ & $\begin{array}{l}\text { Published cases of feline histoplasmosis } \\
\text { worldwide }\end{array}$ \\
\cline { 3 - 4 } & & Country \\
\hline $\begin{array}{c}\text { Cutaneous lesions and pneumonia } \\
\text { (disseminated histoplasmosis) }\end{array}$ & Case 3 & {$[23]$} & Italy \\
& & {$[24]$} & Japan \\
& & {$[3],[4],[17],[25],[26],[27]$,} & USA \\
$\begin{array}{c}\text { Cutaneous lesions with no signs } \\
\text { of respiratory distress }\end{array}$ & Case 2 & - & - \\
$\begin{array}{c}\text { Cutaneous lesions with signs } \\
\text { of respiratory distress }\end{array}$ & Case 1 & {$[5]$} & Brazil
\end{tabular}

our study, younger cats were affected (mean age of 4 years) and no gender predisposition was observed, as described in previous reports [1]. Table 1 summarizes the clinical findings observed in the present reported cases and compares them to previously published reports of feline histoplasmosis.

In vitro susceptibility testing of $H$. capsulatum demonstrated that all strains were susceptible to all tested drugs, with MIC mean values of $0.12 ; 0.016$; 0.12 ; and $6.67 \mu \mathrm{g} / \mathrm{mL}$ for amphotericin $\mathrm{B}$, itraconazole, voriconazole, and caspofungin, respectively, for mycelial phase, and $0.12 ; 0.023 ; 0.002$; and $2 \mu \mathrm{g} / \mathrm{mL}$ for amphotericin $\mathrm{B}$, itraconazole, voriconazole, caspofungin, respectively, for yeast-like phase. MICs for sulfamethoxazole-trimethoprim ranged from $0.08 /$ 0.016 to $0.3 / 0.06$ and from $0.005 / 0.001$ to $0.02 /$ $0.004 \mathrm{mg} / \mathrm{mL}$ for mycelila and yeast-like form, respectively. These findings agree with those from other studies with human strains of $H$. capsulatum [7, 11, 19-21].

Concerning the serological survey, none of the tested felids were positive for Histoplasma antibodies. This survey was performed through immunodiffusion (ID), but this technique presents low sensitivity, when compared to other techniques, such as ELISA [22], which may have compromised the detection of positive animals, considering that human histoplasmosis is highly prevalent in the state of Ceará [2] and that these animals may be equally exposed to this fungus.

These represented the first reports of animal histoplasmosis in the state of Ceará, Brazil, and knowledge on its clinical signs and epidemiology might enable veterinary clinicians to achieve early diagnosis and prescribe an adequate therapy more quickly.
Acknowledgments We would like to thank the financial support given by CAPES (PNPD process number 2103/2009) and CNPq (PROTAX, process number 562296/2010-7).

\section{References}

1. Bromel C, Sykes J. Histoplasmosis in dogs and cats. Clin Tech Small Anim Pract. 2005;20:227-32.

2. Daher EF, Silva GB Jr, Barros FAS, Takeda CFV, Mota RMS, Ferreira MT, Martins JC, Araújo SMHA, GutiérrezAdrianzén AO. Clinical and laboratory features of disseminated histoplasmosis in HIV patients from Brazil. Trop Med Intern Health. 2007;12:1108-15.

3. Hodges RD, Legendre AM, Adams LG, Willard MD, Pitts RP, Monce K, Needels CC, Ward H. Itraconazole for the treatment of histoplasmosis in cats. J Vet Intern Med. 1994;8:409-13.

4. Johnson LR, Fry MM, Anez KL, Proctor BM, Jang SS. Histoplasmosis infection in two cats from California. J Am Anim Hosp Assoc. 2004;40:165-9.

5. Carneiro RA, Lavalle GE, Araújo RB. Histoplasmose cutânea em gato: relato de caso. Arq Bras Med Vet Zootec. 2005;57:158-61.

6. De Hoog GS, Guarro J, Gené J, Figueras M. Atlas of Clinical Fungi. 2rd ed. Reus: Centraalbureau voor Schimmelcultures/Universitat Rovira i Virgili; 2000.

7. Brilhante RS, Fechine MA, Cordeiro Rde A, Rocha MF, Ribeiro JF, Monteiro AJ, de Lima RA, Mesquita JR, de Camargo ZP, Sidrim JJ. In vitro effect of sulfamethoxazoletrimethoprim against Histoplasma capsulatum var. capsulatum. Antimicrob Agents Chemother. 2010;54:3978-9.

8. CLSI (Clinical and Laboratory Standards Institute). Reference method for Broth dilution antifungal susceptilibity testing of filamentous fungi; approved standard, M38-A. CLSI, Pennsylvania, USA; 2002.

9. CLSI (Clinical and Laboratory Standards Institute). Reference method for Broth dilution antifungal susceptibility testing of yeasts; Approved standard-second edition. CLSI, document M27-A2. CLSI, Pennsylvania, USA; 2002.

10. Ajayi BGK, Osuntokun B, Olurin O, Kale OO, Junaid TA. Orbital histoplasmosis due to Histoplasma capsulatum var. duboisii: successful treatment with Septrin. J Trop Med Hyg. 1986;89:179-87. 
11. Li RK, Ciblak MA, Nordoff N, Pasarel L, Warnock DW, McGinnis MR. In vitro activities of voriconazole, itraconazole, and amphotericin B against Blastomyces dermatitidis, Coccidioide immitis, and Histoplasma capsulatum. Antimicrob Agents Chemother. 2000;44:1734-6.

12. Araujo FG. 1st isolation of Histoplasma capsulatum from the soil in Minas Gerais. Rev Inst Med Trop Sao Paulo. 1970;12:185-91.

13. Severo LC, Petrillo VF, Camargo JJ, Geyer GR, Porto NS. Acute pulmonary histoplasmosis and first isolation of Histoplasma capsulatum from soil of Rio Grande do Sul, Brazil. Rev Inst Med Trop Sao Paulo. 1986;28:51-5.

14. Forjaz MHH, Fischman O. Animal histoplasmosis in Brazil. Isolation of Histoplasma capsulatum from a dog on the Northern Coast of São Paulo. Mykosen. 1985;28:191-4.

15. Silva-Ribeiro VL, Ferreira-da-Cruz MF, Wanke B, GalvãoCastro B. Canine histoplasmosis in Rio de Janeiro: natural and experimental infections. J Med Vet Mycol. 1987;25: 319-22.

16. Silva-Vergara ML, Martinez R, Malta MHB, Maffei CML, Ramirez LE. Histoplasma capsulatum isolated from Didelphis albiventris (Marsupialia: Didelphidae) in the state of Minas Gerais, Brazil. Rev Iberoam Micol. 2001; 18:180-2.

17. Clinkenbeard KD, Cowell RL, Tyler RD. Disseminated histoplasmosis in cats: 12 cases (1981-1986). J Am Vet Med Assoc. 1987;190:1445-8.

18. Davies C, Troy GC. Deep mycotic infections in cats. J Am Anim Hosp Assoc. 1996;32:380-91.

19. Kohler S, Wheat LJ, Connolly P, Schnizlein-Bick C, Durkin M, Smedema M, Goldberg J, Brizendine E. Comparison of the echinocandin caspofungina with amphotericin B for treatment of histoplasmosis following pulmonary challenge in a murine model. Antimicrob Agents Chemother. 2000; 44:1850-4.

20. Andreu CMF, León AM, Medina YE, Machin GM, Lancha MRP, Zaragozi MTI. Sensibilidad in vitro de Histoplasma capsulatum var. apsulatum frente a anfotericina B, ketoconazol, itraconazol y fluconazol. Rev Cub Med Trop. 2003;55:76-82.

21. Nakai T, Uno J, Ikeda F, Tawara S, Nishimura K, Miyaji M. In vitro antifungal activity of micafungin (FK463) against dimorphic fungi: comparison of yeast-like and mycelial forms. Antimicrob Agents Chemother. 2003;47:1376-81.

22. Guimarães AJ, Nosanchuk JD, Zancopé-Oliveira RM. Diagnosis of Histoplasmosis. Braz J Microbiol. 2006;37: $1-13$.

23. Mavropoulou A, Grandi G, Calvi L, Passeri B, Volta A, Kramer LH. Quintavalla, C. Disseminated histoplasmosis in a cat in Europe. J Small Anim Pract. 2010;51:176-80.

24. Kobayashi R, Tanaka F, Asai A, Kagawa Y, Ikeda T, Shirota K. A first case report of histoplasmosis in a cat in Japan. J Vet Med Sci. 2009;71:1669-72.

25. Rowley DA, Haberman RT, Emmons CW. Histoplasmosis: pathologic studies of fifty cats and fifty dogs from Loudoun County, Virginia. J Infect Dis. 1954;95:98-108.

26. Mahaffey E, Gabbert N, Johnson D, Guffy M. Disseminated histoplasmosis in three cats. J Am Anim Hosp Assoc. 1977;13:46-51.

27. Noxon JO, Digilio K, Schmidt DA. Disseminated histoplasmosis in a cat: successful treatment with ketoconazole. J Am Vet Med Assoc. 1982;15:817-20.

28. Wolf AM, Belden MN. Feline histoplasmosis: a literature review and retrospective study of 20 new cases. J Am Anim Hosp Assoc. 1984;20:995-8.

29. Aronson E, Bendickson JC, Miles KG, Kintner LD, Schmidt DA. Disseminated histoplasmosis with osseous lesions in a cat with feline lymphosarcoma. Vet Radiol. 1986;27:50-3.

30. Kabli S, Koschmann JR, Robertstad GW, Lawrence J, Ajello L, Redetzke K. Endemic canine and feline histoplasmosis in El paso, Texas. Med Mycol. 1986;24:41-50.

31. Wolf AM. Histoplasma capsulatum osteomyelitis in the cat. J Vet Intern Med. 1987;1:158-62.

32. Tamulevicus AM, Harkin K, Janardhan K, Debey BM. Disseminated histoplasmosis accompanied by cutaneous fragility in a cat. J Am Anim Hosp Assoc. 2011;47:e36. 